\title{
ADUBAÇÃO BÓRICA NA PRODUÇÃO DE FORRAGEM E COMPONENTES RADICULARES DE TREVO BRANCO
}

\author{
WHITE CLOVER ROOTS PRODUCTION AND NODULATION SUBMITTED TO \\ BORON LEVELS
}

\begin{abstract}
Marciela Rodrigues da SILVA ${ }^{1}$; Tangriani Simioni ASSMANN²; Thomas Newton MARTIN ${ }^{3}$; Tatiana da Silva CALDAS ${ }^{4}$

1. Doutoranda no Programa de Pós-Graduação em Produção Vegetal da Universidade Federal do Paraná. marcielarodrigues@ hotmail.com; 2. Professora, Doutora, Universidade Tecnológica Federal do Paraná, Pato Branco, PR, Brasil; 3. Professor, Doutor, Universidade Federal de Santa Maria, Santa Maria, RS, Brasil; 4. Mestre em Agronomia pela Universidade Tecnológica Federal do Paraná, Pato Branco, PR, Brasil.
\end{abstract}

\begin{abstract}
RESUMO: O trevo branco é utilizado no Sul do Brasil conferindo qualidade nas pastagens ao qual se encontra, podendo ser maximizada a sua produção pelo manejo de macro e micronutrientes. Porém, alguns micronutrientes como o boro, possuem limites estreitos entre a deficiência e a toxicidade. Dessa forma, esse trabalho teve por objetivo avaliar os efeitos da aplicação de doses de boro sobre a produção de forragem e componentes radiculares de trevo branco cultivadas em um Latossolo Vermelho distroférrico. $\mathrm{O}$ experimento foi conduzido em casa de vegetação da Universidade Tecnológica Federal do Paraná, localizada no Município de Pato Branco - PR. O delineamento experimental foi inteiramente casualizado, com cinco repetições e os tratamentos consistiram de cinco níveis de boro $\left(0 ; 0,5 ; 1 ; 2\right.$ e $4 \mathrm{~kg} \mathrm{ha}^{-}$ ${ }^{1}$ ). Foram avaliadas as características referentes à produção de raízes, nodulação e matéria seca da parte aérea em plantas de trevo branco. A adubação aumentou a produção de matéria seca de raízes, o número de nódulos e a matéria seca de nódulos até $2,8 \mathrm{~kg}$ de boro ha ${ }^{-1}$, resultando em maior produção de matéria seca de forragem. As maiores taxas, no entanto, apresentaram efeitos negativos sobre a produção de trevo branco, devido à sua toxicidade.
\end{abstract}

PALAVRAS-CHAVE: Trifolium repens L. Boro. Produção de raízes e nódulos.

\section{INTRODUÇÃO}

O trevo branco (Trifolium repens) é uma leguminosa forrageira utilizada tanto em monocultivo como em consórcio com outras espécies, sendo de grande importância na formação de pastagens, por apresentar características, como produção de forragem de alta qualidade, habilidade para competir com gramíneas perenes e alta capacidade de fixação simbiótica de nitrogênio. Além disso, possui teores elevados de proteína bruta com alta digestibilidade, que conferem a essa espécie alto valor nutritivo, possibilitando a sua utilização como alternativa para suprir as necessidades protéicas na alimentação de animais.

A fixação simbiótica de $\mathrm{N}_{2}$ é um dos principais processos que introduzem nitrogênio atmosférico em ecossistemas terrestres. Entre as leguminosas forrageiras, o trevo branco apresenta alta capacidade de incorporar $\mathrm{N}_{2}$ via fixação biológica (FBN) para o sistema de produção, atingindo valores de $200 \mathrm{~kg}$ de $\mathrm{N} \mathrm{ha}^{-1}$ ano $^{-1}$. Para tanto, pode ser crucial para a redução de fertilizantes nitrogenados minimizando assim os custos de produção. No entanto, o estabelecimento de leguminosas pode não ocorrer de maneira adequada caso o solo apresente condições desfavoráveis, tais como baixo $\mathrm{pH}$, e carência de nutrientes como o fósforo e o boro (B) (SMITH et al., 1993).

De maneira geral, a calagem e a adubação fosfatada são práticas comuns em solos cultivados no Sul do Brasil. Contudo, a adubação com B não vem sendo utilizada pela grande maioria dos produtores, podendo ser um dos fatores limitantes ao estabelecimento e a longevidade de fabáceas (HABY et al., 1993). Esse micronutriente participa de importantes processos fisiológicos nas plantas, como transporte de ácido indolacético, atividade da ATPase (GOLDBACH et al., 2001), atuando como um ativador de enzimas presentes em diversos processos metabólicos, tais como transporte de carboidratos, formação de raízes por meio da divisão, alongamento e junção da parede celular e atividade das membranas celulares (MARSCHNER, 1995; LUND et al., 1996; ONO; RODRIGUES 1996). Dentre suas funções, vale mencionar a síntese da parede celular, metabolismo fenólico, do RNA e de carboidratos, além de respiração e lignificação (GUPTA, 1993), sendo o desequilíbrio nutricional desse elemento prejudicial ao crescimento radicular, fixação simbiótica, germinação do grão de pólen e crescimento do tubo polínico (AZEVEDO et al., 2002; EL-HAMDAOUI et al., 2003; BLEVINS; LUKASZEWSKI, 1998). 
De maneira geral, nos estados do RS e SC, teores de $B$ menores que $0,1 \mathrm{mg} \mathrm{kg}^{-1}$ são interpretados como baixo, de 0,1 até $0,3 \mathrm{mg} \mathrm{kg}^{-1}$ como médio e maiores que $0,3 \mathrm{mg} \mathrm{kg}^{-1}$ como altos (COMISSÃO DE QUÍMICA E FERTILIDADE DO SOLO, 2004). No entanto, os níveis críticos de B no solo, assim como a recomendação desse micronutriente, para a pastagem de trevo branco não estão bem estabelecidos para o estado do Paraná, onde esta espécie é cultivada, principalmente, em consórcio com gramíneas. Dificuldades de perenização de trevos quando utilizados em consorciação com gramíneas, tem sido observadas, em sistema de integração lavoura-pecuária. Assmann et al. (2010), em experimentos com consórcio de trevos e aveia, encontraram proporções máximas de trevo de $10,5 \%$ sendo, este, consideradas baixas por Boller e Nösberger (1987) que sugerem uma relação de pelo menos $50 \%$ para que haja uma maior fixação do $\mathrm{N}_{2}$ e assim um maior aproveitamento do nitrogênio pelas gramíneas.

A baixa proporção de trevo encontrada em pastagens consorciadas, bem como a dificuldade de perenização, ocorre, de acordo com Hoglund e Brock (1987), devido à deficiência de macronutrientes e micronutrientes, como a adubação com boro, que não tem sido utilizado na maioria das propriedades.

A deficiência de $\mathrm{B}$ nas plantas tem sido relatada em diferentes condições de solo (SOUZA et al., 2011; JONES JÚNIOR, 1983). Pesquisas em solos do estado do Paraná constataram que apenas 15,5\% das 635 amostras de solo avaliadas mostramse com níveis adequados desse elemento (LUCHESE et al., 1994), sugerindo a possibilidade de resposta a sua aplicação nos demais solos amostrados. Estudos relacionados com a eficiência da utilização de boro na cultura do trevo são limitados, apesar de conhecerem-se as diversas funções do elemento na fisiologia das plantas. Dessa forma, objetivou-se com esse estudo avaliar o efeito da aplicação de boro na produção de raízes, nódulos e matéria seca da parte aérea de plantas de trevo branco, cultivadas em solo Latossolo Vermelho distroférrico.

\section{MATERIAL E MÉTODOS}

O trabalho experimental foi conduzido em casa de vegetação, na Universidade Tecnológica Federal do Paraná (UTFPR) localizada no município de Pato Branco - PR nas coordenadas 2507's, $52^{\circ} 41^{\prime} \mathrm{W}$ e altitude de $700 \mathrm{~m}$, no período de novembro de 2009 a outubro de 2010. O clima predominante é do tipo subtropical úmido $(\mathrm{Cfb})$, segundo a classificação de Köppen (MAACK, 1968). O solo utilizado no experimento é classificado como LATOSSOLO VERMELHO distroférrico, de textura argilosa, formado a partir de rocha eruptiva básica (BHERING et al., 2008).

As unidades experimentais consistiram de vasos com capacidade para $3 \mathrm{~L}$, nos quais foram adicionados $4 \mathrm{~kg}$ de substrato oriundo de um solo coletado na profundidade 0,0 a $0,20 \mathrm{~m}$, cuja análise química e granulométrica apresentou: $\mathrm{pH}\left(\mathrm{CaCl}_{2}\right)$ : 5,00; P: 17,34 mg dm${ }^{-3}$; MO: 67,01 $\mathrm{g} \mathrm{dm}^{-3}$; K: 1,08 $\mathrm{mg} \mathrm{dm}$; B: $0,14 \mathrm{mg} \mathrm{kg}^{-1}$; $\mathrm{Al}^{3+}: 0,00$; Ca: 6,59 $\mathrm{cmol}_{(\mathrm{c})} \mathrm{dm}^{-3} ; \mathrm{Mg}: 2,81 \mathrm{cmol}_{(\mathrm{c})} \mathrm{dm}^{-3} ; \mathrm{H}+\mathrm{Al}: 4,59$ $\mathrm{cmol}_{(\mathrm{c})} \mathrm{dm}^{-3}$; V\%: 69,54; argila: $61,9 \%$; silte: $35,5 \%$ e areia: $2,6 \%$.

O delineamento experimental foi inteiramente casualizado com cinco repetições. Sendo os tratamentos constituídos de cinco níveis de B $\left(0 ; 0,5 ; 1 ; 2\right.$ e $\left.4 \mathrm{~kg} \mathrm{ha}^{-1}\right)$, aplicados na forma de Bórax $\left(\mathrm{Na}_{2} \mathrm{~B}_{4} \mathrm{O}_{7} \cdot 10 \mathrm{H}_{2} \mathrm{O}, \quad 11,3 \%\right.$ de boro) incorporados ao solo no momento do preparo do vaso. A dose padrão de B utilizada como referência $\left(2,0 \mathrm{~kg} \mathrm{ha}^{-1}\right)$ é equivalente à sugerida pela CQFSRS/SC (2004) para plantas de alfafa, sendo as demais compostas pela testemunha, um quarto, metade e o dobro da dose padrão.

A semeadura do trevo branco foi realizada após as aplicações dos tratamentos utilizando-se o equivalente a três $\mathrm{kg} \mathrm{ha}^{-1}$ de sementes da cultivar Yi, previamente peletizadas com calcário e inoculadas com bactéria específica do gênero Rhizobium. Após o desbaste foram cultivadas cinco plantas por vaso, sendo a irrigação realizada diariamente, de forma manual, com 0,5 litros de água por unidade experimental. Para determinação da matéria seca da parte aérea realizaram-se cortes sempre que $50 \%$ das unidades experimentais apresentassem pelo menos $10 \%$ de florescimento. A coleta dos dados de produção de raiz e nodulação foi realizada aos 360 dias após a emergência. As plantas foram retiradas cuidadosamente do solo, cortadas na base do caule separando-se a parte aérea das raízes. Em seguida, os nódulos foram destacados e contados. As amostras obtidas com a separação foram colocadas para secar em estufa a $65^{\circ} \mathrm{C}$ por 72 horas (ou massa constante), sendo em seguida determinada sua massa.

Os resultados experimentais foram submetidos à análise de variância (teste F) com nível de significância de 5\%. Quando os resultados foram significativos, foram ajustadas regressões polinomiais entre os níveis de $\mathrm{B}$ (variável independente) e as demais variáveis dependentes. Foram testados os modelos, linear, quadrático e cúbico e a escolha baseada no maior grau 
significativo. A máxima eficiência técnica (MET) foi obtida a partir do ponto de máxima de uma equação de segundo grau, calculado igualando-se a zero a derivada de primeira da equação e encontrando-se posteriormente o valor de x. O software utilizado na análise estatística foi o Genes (CRUZ, 2006).

\section{RESULTADOS E DISCUSSÃO}

$\mathrm{O}$ experimento desenvolveu-se sem que pragas, doenças ou plantas daninhas pudessem interferir no desenvolvimento da cultura. De modo geral, o efeito da adubação boratada foi de natureza quadrática sobre as características avaliadas, sendo que a presença de teores acima de $3,28 \mathrm{~kg} \mathrm{ha}^{-1}$ de $\mathrm{B}$ no solo passaram a prejudicar o desenvolvimento das plantas. Esses resultados concordam com os obtidos por Corrêa et al. (2006), em experimento realizado com três doses de $\mathrm{B}\left(0,6\right.$ e $\left.12 \mathrm{~kg} \mathrm{ha}^{-1}\right)$ onde a aplicação de $12 \mathrm{~kg} \mathrm{ha}^{-1}$ foi prejudicial tanto à produção de matéria seca da parte aérea como de

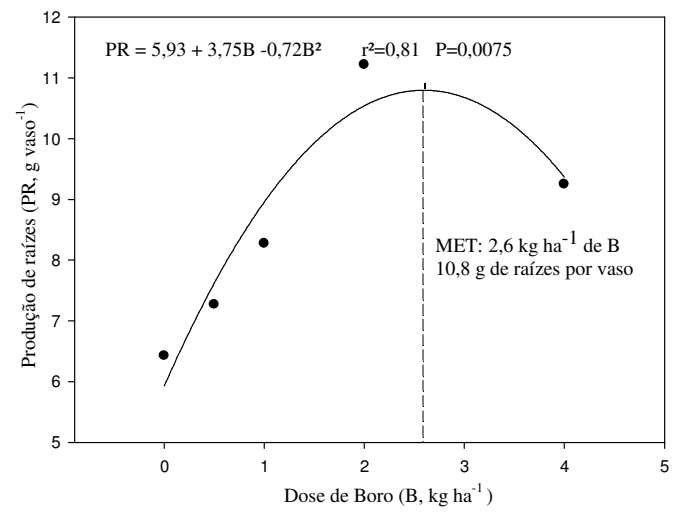

(a)

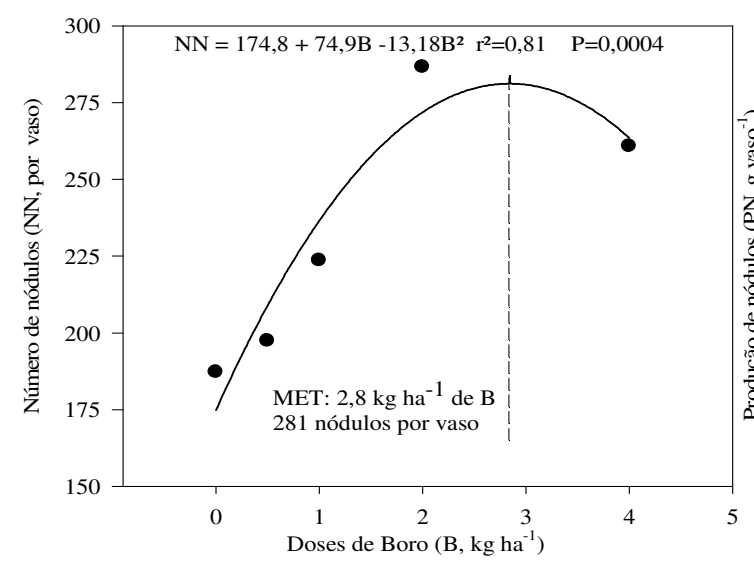

(c) raiz para a cultura do arroz, sendo que o processo de toxidez iniciou-se na dose de $6 \mathrm{~kg} \mathrm{ha}^{-1}$. Em trabalho realizado por Azevedo et al. (2002) as doses zero e $12 \mathrm{~kg} \mathrm{ha}^{-1}$ proporcionaram sintomas visuais típicos de deficiência e toxidez de $\mathrm{B}$, respectivamente.

Nas avaliações referentes à produção de raiz, a máxima eficiência técnica foi obtida com a aplicação de $2,6 \mathrm{~kg} \mathrm{~B} \mathrm{ha}{ }^{-1}$, que resultou em uma produção de $10,8 \mathrm{~g}$ de raízes por vaso, correspondendo a um acréscimo de 83,05\% em relação à testemunha, indicando que esse elemento promove o crescimento das mesmas, o que pode ser importante para o crescimento das plantas, especialmente em condições de deficiência hídrica (Figura 1). Esta resposta na produção de massa seca do sistema radicular pode estar relacionada aos efeitos do B, nas funções relacionadas ao crescimento meristemático, por fazer parte dos polissacarídeos da parede celular, estimulando o desenvolvimento e o alongamento celular (MALAVOLTA et al., 1997).

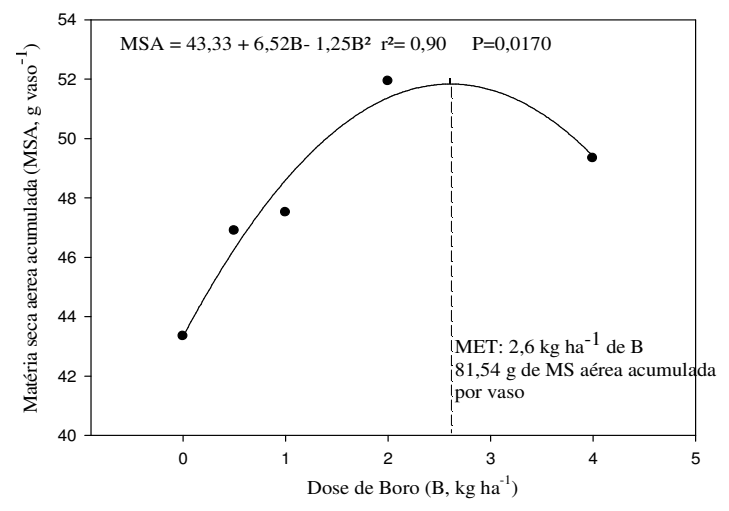

(b)

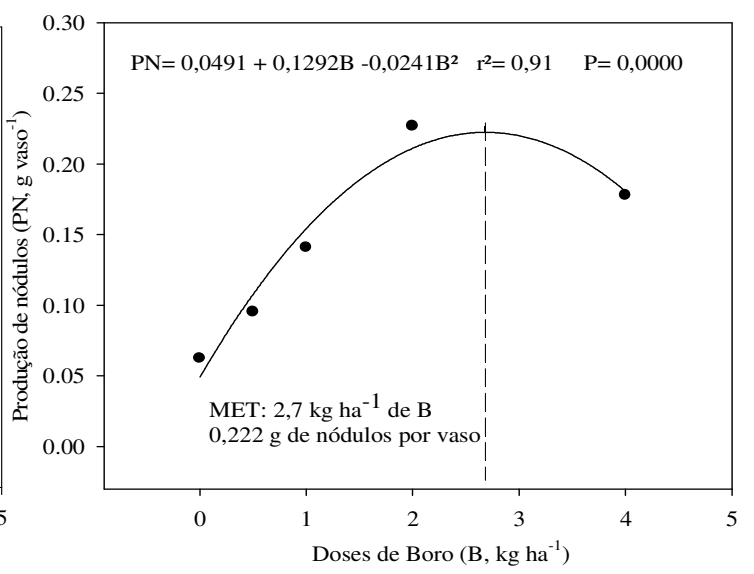

(d)

Figura 1. Produção de raízes (a), produção de matéria seca aérea total acumulada (b), número de nódulos (c) e produção de matéria seca de nódulos (d) de trevo branco (Trifolium repens L.) em função da aplicação de doses de boro e máxima eficiência técnica (MET). 
Estes resultados estão de acordo com os dados observados por Lenoble et al. (1996), que verificaram que o uso de $2,24 \mathrm{~kg} \mathrm{ha}^{-1}$ de boro em plantas de alfafa estimulou o crescimento das raízes em até $330 \%$ em relação às plantas que não foram suplementadas com boro. Da mesma forma, Asad et al. (2001), observaram que raízes de girassol paralisam o seu desenvolvimento seis horas após a retirada de $\mathrm{B}$ do meio de crescimento. Favareto et al. (2007), avaliando a resposta de plantas de trevo a seis doses de B $\left(0 ; 0,25 ; 0,5 ; 0,75 ; 1,0\right.$ e $\left.2.0 \mathrm{~kg} \mathrm{ha}^{-1}\right)$ observaram que a matéria seca de raízes foi significativamente maior nos tratamentos com aplicação de boro em comparação com a testemunha, independente da dose aplicada.

A Figura 1 demonstra que as doses de B influenciaram a nodulação das plantas, sendo a maior quantidade de nódulos observada na dose de $2,81 \mathrm{~kg} \mathrm{ha}^{-1}$ de $\mathrm{B}$ e a maior produção de matéria seca de nódulos evidenciada na dose de $2,7 \mathrm{~kg} \mathrm{ha}^{-1}$ de $\mathrm{B}$, alcançando 281 nódulos, vaso $^{-1}$ e $0,222 \mathrm{~g}$ vaso $^{-}$

${ }^{1}$ de nódulos, respectivamente. Esses resultados são semelhantes aos observados em trabalho realizado por Bonilla et al. (1997) onde a nodulação das raízes de feijão com deficiência de boro foi baixa em relação à nodulação com níveis suficientes desse nutriente. Da mesma forma, Zehirov e Georgie (2001), verificaram que a deficiência de boro afetou o crescimento dos nódulos, em plantas de soja. Werner e Matos (1974) realizaram um experimento fatorial com boro $\left(0,5 \mathrm{~kg} \mathrm{ha}^{-1}\right)$, cobre $\left(2,0 \mathrm{~kg} \mathrm{ha}^{-1}\right)$, molibdênio $\left(0,25 \mathrm{~kg} \mathrm{ha}^{-1}\right)$ e zinco $\left(2,0 \mathrm{~kg} \mathrm{ha}^{-1}\right)$ em um Latossolo vermelho-escuro, e constaram que a aplicação de Boro resultou em aumentos significativos no número e massa de nódulos e na produção de massa seca de plantas de soja-perene Comum. Azevedo et al. (2002) avaliando a relação entre a massa seca de nódulos, das raízes de plantas de ervilha, em razão da aplicação de boro nos solos Gleissolo Háplico e Organossolo Mésico artificialmente drenado, observaram um menor valor nos pesos secos dos nódulos na dose zero. Yamagishi e Yamamoto (1994) também constataram menores valores de peso seco em nódulos de raízes de soja, na ausência de boro. Bolaños et al. (1994), observaram nódulos necróticos e não funcionais na ausência de $B$, afirmando que os danos na estrutura e função dos nódulos foram causados, provavelmente, pela degeneração das paredes celulares destes.

A relação entre a produção da matéria seca da parte aérea e as doses aplicadas ajusta um modelo quadrático, o que indica que um menor valor na matéria seca da parte aérea foi observado na dose zero. As doses de B estimadas com relação à matéria seca máxima da parte aérea foi $2,6 \mathrm{~kg}$ de $\mathrm{B} \mathrm{ha}{ }^{-1}$, resultando em um acréscimo de $90 \% \mathrm{em}$ relação à testemunha (Figura 1), sendo provável que o B adicionado tenha estimulado a atividade meristemática das células, influenciando na elongação e diferenciação celular. Essa resposta em termos de aumento de matéria seca à adição de $\mathrm{B}$ também pode ser explicada pelas afirmações de Dechen e Nachtigall (2007) que relataram a atuação do $\mathrm{B}$, na atividade de hormônios, e em processos biológicos como fotossíntese, metabolismo de carboidratos e do nitrogênio, influenciando à divisão celular e o acúmulo de biomassa, nos pontos de crescimento, o que poderia resultar em aumento de matéria seca da parte aérea. Respostas similares foram observadas por Favaretto et al. (2007), em experimento com Trifolium vesiculosum que obtiveram um incremento de $130 \%$ na produção de matéria seca com uso de boro. Em trabalho realizado por Fageria (2000) o boro influenciou a produção de matéria seca da parte aérea e de raízes de arroz, feijão, milho, soja e trigo, sendo que as respostas variaram conforme a cultura. As dosagens que propiciaram a máxima produção de matéria seca da parte aérea variaram entre 0,4 e $7 \mathrm{mg} \mathrm{de} \mathrm{B} \mathrm{kg}^{-1} \mathrm{de}$ solo aplicado e as doses tóxicas variaram de 3 a 8,7 mg $\mathrm{B} \mathrm{kg}{ }^{-1}$ de solo aplicado. Similarmente ao encontrado para trevo neste trabalho, alta resposta a doses de boro foram observadas para milho (LIMA et al., 2007). Gupta (1984) obteve aumentos na produção de massa seca de plantas de alfafa devido à adição de boro em solos podzólicos do leste catarinense. Experimentos com plantas de alfafa verificaram que a adição de boro promoveu incrementos significativos na produção de massa seca da planta e na concentração desses micronutrientes no tecido vegetal (SHERREL, 1983; GUPTA; MACLEOD 1977). Santos et al. (2004), em estudo sobre produção de alfafa em função do suprimento de boro em solução nutritiva, obtiveram aumentos na produção de massa seca devido à aplicação do micronutriente. Da mesma forma, Lenoble et al. (1996), encontraram que o uso em média de 2 a $3 \mathrm{~kg} \mathrm{ha}^{-1}$ aumentaram a produção de fabáceas, como a alfafa. Souza et al. (2011) avaliando os efeitos da aplicação de calcário e boro nos atributos químicos de um Latossolo, estado nutricional e produtividade do feijoeiro observou que a cultura respondeu à adubação boratada, tendo atingido bons índices de produção com a utilização de $1,8 \mathrm{~kg} \mathrm{ha}^{-1}$ de $\mathrm{B}$.

Em termos gerais, o desenvolvimento de plantas de trevo branco é favorecido em condições adequadas de disponibilidade de boro e por isso a aplicação da dose correta desse micronutriente é de 
grande importância, sendo a sua deficiência prejudicial à cultura. Da mesma forma, a presença de boro em excesso, ou seja, a utilização de doses superiores a $3 \mathrm{~kg} \mathrm{ha}^{-1}$, o que corresponderia a teores próximos a $3,28 \mathrm{~kg} \mathrm{ha}^{-1}$ de $\mathrm{B}$ no solo, reduzem à produção de matéria seca de raízes, à produção e número de nódulos e, consequentemente, a absorção de água, nutrientes e à fixação de nitrogênio atmosférico, cujo decréscimo observado nas doses mais altas indica um possível efeito tóxico desse nutriente. De modo geral, a máxima produção de raízes e matéria seca da parte aérea foi obtida com a dose de 2,6 $\mathrm{kg}_{\text {de }} \mathrm{B} \mathrm{ha}{ }^{-1}$. Dose essa, muito próxima das que são necessárias para a máxima produção de matéria seca e número de nódulos $(2,7$ e 2,8 kg de $\mathrm{B}$ ha $^{-1}$, respectivamente).

A estreita relação entre deficiência e excesso de $\mathrm{B}$ observada neste experimento também foi relatada em trabalho realizado por Furlani et al. (2001), avaliando a resposta de cultivares de soja a adição de doses de boro em solução nutritiva, onde o sintoma inicial de toxidez foi observado a partir da dose de $0,8 \mathrm{mg} \mathrm{L}^{-1}$ de $\mathrm{B}$ na solução, enquanto que o acúmulo máximo de matéria seca total ocorreu para concentrações na solução estimadas entre 0,1 e 0,2 $\mathrm{mg} \mathrm{L}^{-1}$. Corrêa et al. (2006) estudando a influência das doses de boro no crescimento radicular e da parte aérea em plantas de arroz, verificaram que a dose de $12 \mathrm{~kg} \mathrm{ha}^{-1}$ foi tóxica em relação a dose de 0 $\mathrm{kg} \mathrm{ha}^{-1}$. No entanto, já na dose de $6 \mathrm{~kg} \mathrm{ha}^{-1}$ iniciouse o processo de toxidez. A matéria seca aérea acumulada apresentou uma elevada correlação linear positiva $(0,96)$ com a produção de raízes (Figura 2), caracterizando aumento na produção de forragem com o acréscimo no desenvolvimento radicular.
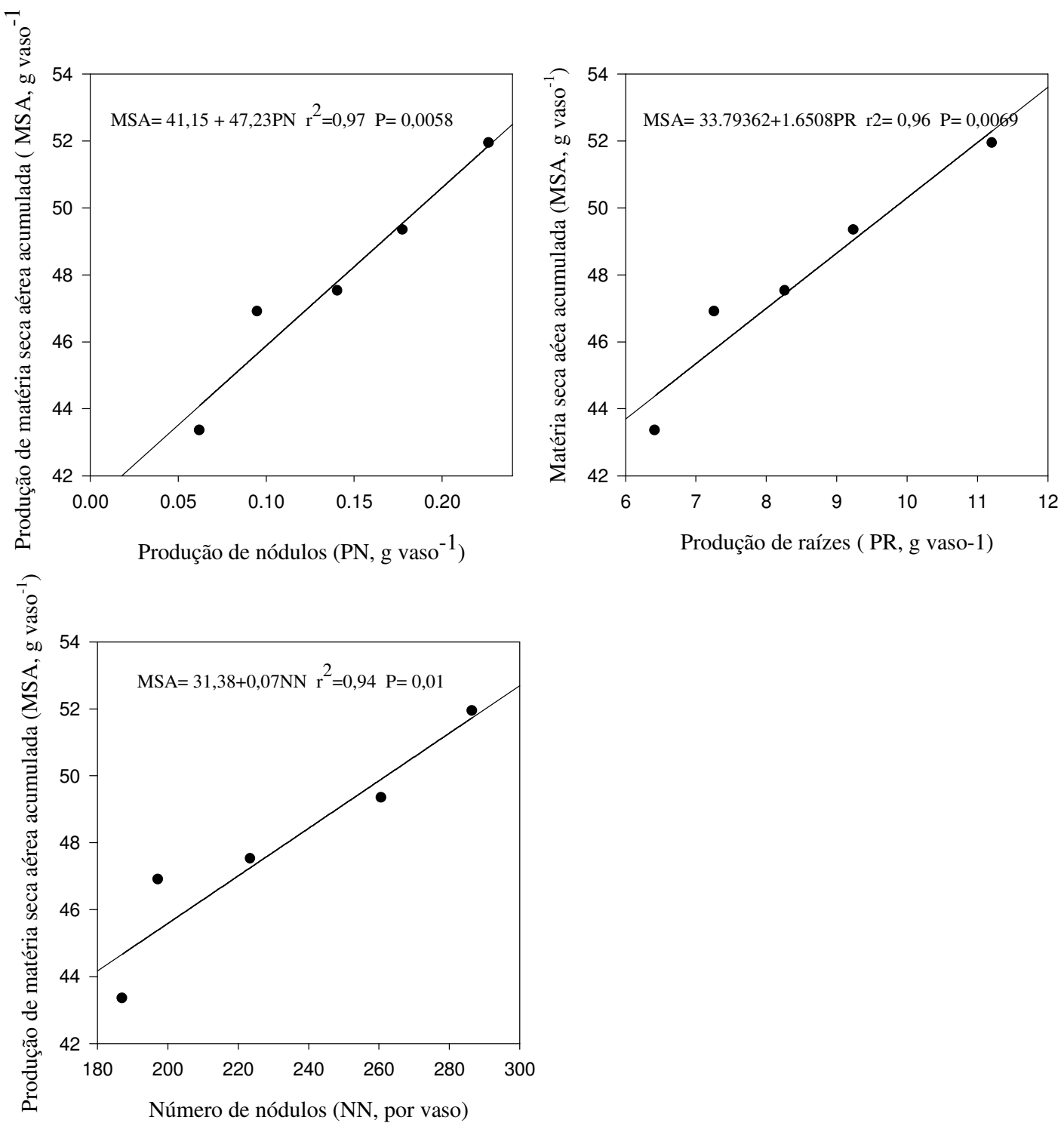

Figura 2. Relação entre a produção de matéria seca aérea total acumulada, a produção de raízes, nódulos e o número de nódulos de trevo branco (Trifolium repens $\mathrm{L}$.). 
Da mesma forma, a produção de matéria seca da parte aérea se correlacionou positivamente com a nodulação. Conforme observado anteriormente para a produção de raízes, a equação mostrou aumento na produção de forragem à medida que se aumentaram o número e a massa seca de nódulos. Possivelmente, a contribuição de B no aumento da nodulação, no maior crescimento radicular e, consequentemente na produção de forragem, é devido ao seu impacto na atividade de enzimas e fornecimento de produtos da fotossíntese. Em trabalho realizado por Souza et al. (2011) avaliando o efeito de doses de boro na parte aérea de plantas de maracujazeiro amarelo, observaram que a matéria seca da parte aérea apresentou comportamento quadrático, em função das doses de $\mathrm{B}$, como consequência dos incrementos promovidos nas características de desenvolvimento, tais como diâmetro do caule, altura e área foliar das plantas.

\section{CONCLUSÕES}

A adubação aumentou a produção de matéria seca de raízes, o número de nódulos e a matéria seca de nódulos até a dose de $2,8 \mathrm{~kg}$ de $\mathrm{B}$ $\mathrm{ha}^{-1}$, resultando em maior produção de matéria seca de forragem.

As maiores taxas, no entanto, apresentaram efeitos negativos sobre a produção de trevo branco, devido à sua toxicidade.

\begin{abstract}
The white clover (Trifolium repens L.) is used in southern Brazil in giving quality pasture as you are and can be maximized by managing their production of macro and micronutrients. However, some micronutrients such as boron, have narrow limits between deficiency and toxicity. Thus, this study aimed to evaluate the effects of doses of boron application on the production of forage and root components of white clover grown on an Oxisol. The experiment was conducted in a greenhouse at the Federal Technological University of Parana, located in the city of Pato Branco - PR. The experimental design was completely randomized design with five replications and treatments consisted of five levels of boron $\left(0,0.5,1,2\right.$ and $\left.4 \mathrm{~kg} \mathrm{ha}^{-1}\right)$. We evaluated the characteristics concerning the production of roots, nodulation and dry matter of shoots of white clover plants. Fertilization increased the production of root dry weight, nodule number and nodule dry matter up to $2.8 \mathrm{~kg} \mathrm{ha}^{-1}$ of boron, resulting in higher production of herbage. Higher rates, however, had negative effects on the production of white clover, due to its toxicity.
\end{abstract}

KEYWORDS: Trifolium repens L. Boron. Production of roots and nodules.

\title{
REFERÊNCIAS
}

ASAD, A. et al. A critical comparison of the external and internal boron requirements for contrasting species in boron-buffered solution culture. Plant and Soil, Dordrecht, v. 233, n. 1, p. 31-45, 2001. Disponível em: < www.springerlink.com/content/h1v14253838720q6/fulltext.pdf > Acesso em: 30 jun. 2011.

ASSMANN, T. S. et al. Produção de gado de corte e de pastagem de aveia em sistema de integração lavourapecuária em presença e ausência de trevo e nitrogênio. Revista Brasileira de Zootecnia, Viçosa, v. 39, n. 7, p. 1387-1397, 2010. Disponível em: < www.scielo.br/pdf/rbz/v39n7/a01v39n7.pdf > Acesso em: 30 jun. 2011. doi: http://dx.doi.org/10.1590/S1516-35982010000700001

AZEVEDO, W. R. de et al. Efeito do boro na nodulação da ervilha cultivada em solos de várzea. Pesquisa Agropecuária Brasileira, Brasília, v. 37, n. 8, p. 1137-1143, 2002. Disponível em: < www.scielo.br/pdf/pab/v37n8/11673.pdf > Acesso em: 30 jun. 2011. http://dx.doi.org/10.1590/S0100204X2002000800011

BHERING, S. B. et al. 2008. Mapa de solos do Estado do Paraná: legenda atualizada. Rio de Janeiro: EMBRAPA/IAPAR. 74pp.

BLEVINS, D. G.; LUKASZEWSKI, K. M. Boron in plant structure and function. Annual Review of Plant Physiology and Plant Molecular Biology, Palo Alto, v. 49, p. 481-500, 1998. Disponível em: < http://www.ncbi.nlm.nih.gov/pubmed/15012243 > Acesso em: 30 jun. 2011. 
BOLAÑOS, L. Essentially of boron for symbiotic dinitrogen fixation in pea (Pisum sativum) rhizobium nodules. Plant Physiology, Rockville, v. 104, p. 85-90, 1994.

BOLLER, B. C.; NÖSBERGER, J. Symbiotically fixed nitrogen from field-grown white and red clover mixed with ryegrasses at low levels of N15 fertilization. Plant and Soil, Dordrecht, v. 104, n. 2, p. 219-226, 1987. http://dx.doi.org/10.1007/BF02372535

BONILLA I. et al. The aberrant cell walls of boron deficient bean root nodules have no covalently-bound hydroxyproline/proline-rich proteins. Plant Physiology, Rockville, n. 115. p. 1329-1340, 1997. Disponível em: < www.plantphysiol.org/content/115/4/1329.full.pdf > Acesso em: 30 jun. 2011.

COMISSÃO DE QUÍMICA E FERTILIDADE DO SOLO, Manual de adubação e calagem para os Estados do Rio Grande do Sul e Santa Catarina, 10 ed., Porto Alegre, SBCS 2004. 400 p.

CORRÊA, J. C. et al. Doses de boro e crescimento radicular e da parte aérea de cultivares de arroz de terras altas. Revista Brasileira de Ciência do Solo, Viçosa, v. 30, 1077-1082, 2006. Disponível em: < www.scielo.br/pdf/rbcs/v30n6/a17v30n6.pdf > Acesso em: 30 jun. 2011. http://dx.doi.org/10.1590/S010006832006000600017

CRUZ, C. D. Programa Genes: biometria. Viçosa: Imprensa Universitária, 480p. 2006.

DECHEN, A. R.; NACHTIGALL, G. R. Elementos requeridos à nutrição de plantas. In: NOVAIS, R. F. et al. Fertilidade do solo. Viçosa: Sociedade Brasileira de Ciência do Solo, 2007. p. 91-132.

EL-HAMDAOUI, A. et al. Effects of boron and calcium nutrition on the establishment of the Rhizobium leguminosarum-pea (Pisum sativum) symbiosis and nodule development under salt stress. Plant, Cell and Environment, Ansterdan, v. 26, p. 1003-1011, 2003. Disponível em: < http://onlinelibrary.wiley.com/doi/10.1046/j.1365-3040.2003.00995.x/pdf > Acesso em: 30 jun. 2011. http://dx.doi.org/10.1046/j.1365-3040.2003.00995.x

FAGERIA, N. K. Níveis adequados e tóxicos de boro na produção de arroz, feijão, milho, soja e trigo em solo de cerrado. Revista Brasileira de Engenharia Agrícola e Ambiental, Campina Grande, v.4, n.1, p.57-62, 2000. Disponível em: < http://www.scielo.br/pdf/rbeaa/v4n1/v4n1a11.pdf > Acesso em: 30 jun. 2011. http://dx.doi.org/10.1590/S1415-43662000000100011

FAVARETTO, N. et al. Shoot and root responses of Trifolium vesiculosum to boron fertilization in an acidic Brazilian soil. Brazilian Archives of Biology and Technology, Curitiba, v.50, n.4, p. 597-604, 2007.

Disponível em: < http://www.scielo.br/pdf/babt/v50n4/05.pdf > Acesso em: 30 jun. 2011 http://dx.doi.org/10.1590/S1516-89132007000400005

GOLDBACH, H. E.; YU, Q.; WINGENDER, R.; SCHULZ, M.; WIMMER, M.; FINDEKLEE, P.; BALUSKA, R. Rapid response reactions of roots to boron deprivation. Journal Plant Nutrition Soil Science, Greenwood, v. 164, p. 173-181, 2001.

GUPTA, U. C.; MACLEOD, J. A. Influence of calcium and magnesium sources on boron uptake and yield of alfafa and rutabages as related to soil pH. Soil Science, Madison, v. 124, p. 279-284, 1977.

http://dx.doi.org/10.1097/00010694-197711000-00004

GUPTA, U.C. Boron nutrition of alfalfa, red clover and timothy grown on Podzol soils of eastern Canada. Soil Science, Madison, v. 137, p. 16-22, 1984. http://dx.doi.org/10.1097/00010694-198401000-00003

HABY, V. A. et al. Boron Improves Clover Production. Better Crops With Plant Food, Norcross, v. 77, n. 3 , p. 20-21, 1993.

HOGLUND J. H.; BROCK, J. L. Nitrogen fixation in managed grasslands. In: Sanaydon, R. W. (ed.) Managed Grasslands: analytical Studies. Amsterdam: Elsevier, p. 187-196, 1987. 
JONES JÚNIOR, J. B. Análisis de los tejidos de las plantas para micronutrientes. In: Mortevedt, J. J. et al. (Comp.). Micronutrientes en agricultura. México: AGT Editor, p. 349-378, 1983.

LENOBLE, M. E. et al. Prevention of aluminum toxicity with supplemental boron. II. Stimulation of root growth in an acidic, high-aluminium subsoil. Plant, Cell and Environment, Ansterdan, v. 19, p. 1143-1148, 1996. Disponível em: < http://onlinelibrary.wiley.com/doi/10.1111/j.1365-3040.1996.tb00429.x/abstract > Acesso em: 30 jun. 2011. http://dx.doi.org/10.1111/j.1365-3040.1996.tb00429.x

LIMA, J. C. P. S. et al. Níveis críticos e tóxicos de boro em solos de Pernambuco determinados em casa de vegetação. Revista Brasileira de Ciência do Solo, Viçosa, v. 31, p. 73-79, 2007. Disponível em: < http://www.scielo.br/pdf/rbcs/v31n1/08.pdf > Acesso em: 30 jun. 2011. http://dx.doi.org/10.1590/S010006832007000100008

LUCHESE, E. B. et al. Levantamentos preliminares dos teores de boro nos solos do Paraná. Brazilian Arquives Biology Tecnology, Curitiba, v. 37, n. 2, p. 345-351, 1994.

LUND, S. T. et al. Cuttings of tabacco mutant, rac, undergo cell divisions but do not initiate adventitious roots inresponse to exogenous auxina. Physiology Plantarum, Copenhagen, v. 97, p. 372-380, 1996.

http://dx.doi.org/10.1034/j.1399-3054.1996.970223.x

MAACK, R. 1968. Geografia física do Estado do Paraná. Curitiba: Banco do Desenvolvimento do Paraná. $350 \mathrm{pp}$.

MALAVOLTA, E.; VITTI, G. C.; OLIVEIRA, S. A. Avaliação do estado nutricional das plantas: princípios e aplicações. 2. ed. Piracicaba: Associação Brasileira para Pesquisa da Potassa e do Fosfato, 1997.

MARSCHNER, H. Mineral nutritions of higher plants. London : Academis Press, 1995, 889p.

ONO, E. O.; RODRIGUES, J. D. Aspecto da fisiologia do enraizamento de estacas caulinares. Jaboticabal, Universidade Estadual Paulista, 1996. 83p.

SANTOS, A. R. et al. Boron nutrition and yield of alfafa cultivar crioula in relation to boron supply. Scientia Agricola, Piracicaba, v.61, p.496-500, 2004. Disponível em: < www.scielo.br/pdf/sa/v61n5/21448.pdf > Acesso em: 30 jun. 2011. http://dx.doi.org/10.1590/S0103-90162004000500006

SHERREL, C. G. Comparison of materials of different solubility as source of boron for plants. New Zealand Lournal of Experimental Agriculture, Wellington, v. 11, p. 325-329,1983.

SMITH, G. R. et al. Effects of Boron on Seedling Establishment of Annual Legumes. Better Crops With Planta Food, Norcross, v. 77, n. 3, p. 18-19, 1993.

SOUZA, H. A.; NATALE, W.; ROZANE, D. E.; HERNANDES, A.; ROMUALDO, L. M. Calagem e adubação boratada na produção de feijoeiro. Revista Ciência Agronômica, Fortaleza, v. 42, n. 2, p. 249-257, 2011. http://dx.doi.org/10.1590/S1806-66902011000200001

WERNER, J. C.; MATTOS, H. B. Ensaio de fertilização com micronutrientes em soja-perene, Glycine wightii, wild. Boletim de Industria Animal, São Paulo, v. 31, p. 313-324, 1974.

YAMAGISHI, M.; YAMAMOTO, Y. Effects of boron on nodule development and symbiotic nitrogen fixation in soybean plants. Soil Science and Plant Nutrition, Tokyo, v. 40, v. 2, p. 265-274, 1994. 